\title{
Las mujeres en la Guerra de la Independencia y en la Constitución de 1812. Análisis desde la epistemología feminista y de género
}

\author{
Amelia Sanchís Vidal \\ dh1savia@uco.es \\ $M^{a}$ José Ramos Rovi \\ hi1rarom@uco.e
}

https://dx.doi.org/10.12795/futhark.2013.i08.14

"It is far harder to kill a phantom than a reality" Virginia Woolf

\begin{abstract}
Madrid, 1808, the war against French broke out. Isla de León, 1810 , the constituent period started. Throughout these two historical events, women were not given any chance. This has led the authors of this paper to ponder upon the following questions: were women objects or subjects? If subjects, were they ever unrestrained from being such? If objects, when will women be subjects without being restrained from being such? We strongly believe that the answers to these questions will be different depending on the epistemological and methodological models employed in a historical and legal research.

Keywords: Spanish Constitution of 1812, rights, epistemology, gender, women.

Resumen: Madrid, 1808, comienza la guerra contra el francés. Isla de León, 1810, comienza el periodo constituyente. Durante estos dos hechos históricos, poco chance se les dio a las mujeres. Lo que ha llevado a preguntarnos: ¿la mujer era objeto o sujeto? Y si sujeto ¿alguna vez dejó de estar sujeta? Y ¿para cuándo las mujeres serán "sujetas" sin estar sujetas? Consideramos que las respuestas a estas preguntas serán diferentes según los modelos epistémicos y metodológicos que se empleen en una investigación histórica y jurídica.
\end{abstract}


Palabras clave: Constitución 1812, derechos, epistemología, género, mujeres.

\section{I.- INTRODUCCIÓN}

La participación de las mujeres en los conflictos armados, ha sido una constante a lo largo de la historia y, sin embargo, cuando ha llegado la paz, las mujeres se han quedado al margen de la historia y del derecho. Por ello, en la Conferencia Mundial de los Derechos Humanos (Viena 1993) se afirmó que los derechos humanos también son derechos de las mujeres.

El uso de las epistemologías neutrales empleadas en las macroáreas de ciencias humanas y en las de ciencias sociales y jurídicas siempre nos indicaban dónde estaban los varones pero: ¿dónde estaban las mujeres y sus saberes? Necesitábamos de otras epistemologías para visibilizarlos. Era irónico que estas investigaciones, supuestamente neutrales, dejaran fuera a más de la mitad de la población humana. Las epistemologías y metodologías tradicionales, denominadas neutras consideran que deben centrarse en lo cognitivo y abandonar lo político, lo ideológico y social. También consideran que el lenguaje es asexual, quizá porque la mayoría de los investigadores eran varones y por extensión hacían del masculino el sujeto universal. Así pues, sus postulados y fuentes no daban cabida a otras formas de elaborar los conocimientos.

De hecho, las mujeres han sido apartadas de la instrucción, del estudio y después no han podido legitimar sus investigaciones debido a que la metodología tradicional las consideraba acientíficas, con poco rigor. La epistemología feminista y de género, los conocimientos situados y la reivindicación de fuentes poco convencionales, están proporcionando otros datos están resultando inestimables para completar investigaciones ya realizadas o bien para comenzar otras cuyos resultados visibilizan a mayor número de población y conocimientos. Se explicita desde dónde se investiga y cuáles son las circunstancias desde las que se realizan los estudios. En realidad, consideramos que las nuevas propuestas epistémicas son otras formas de poder al nombrar, sistemáticamente, desde la conciencia feminista, sujetos y objetos. Estas nuevas epistemologías sí creen que es ético que el conocimiento conlleve posturas políticas con responsabilidades específicas. Estamos convencidas de que el saber sí tiene consecuencias, y la docencia una repercusión inimaginable.

Frente a las epistemologías de corte tradicional, la presente investigación la hemos realizado bajo el prisma de una epistemología feminista y de género, no pertenece a las llamadas ciencias 'neutrales' ni 'duras', 
e intenta dejar al menor número de personas invisibles, o en los márgenes. Deja de ser una investigación neutra para centrase en el estudio de las mujeres de esa época. Además, consideramos al lenguaje un constructor y planteamos el género como un método de investigación. Creemos que el conocimiento conlleva una postura política con una responsabilidad. En concreto, siguiendo la taxonomía propuesta por Sandra Harding, realizamos un análisis revisionista del periodo de la Constitución de 1812, con motivo de su reciente bicentenario, desde la epistemología jurídica e histórica feminista. De otro lado, empleando el empirismo feminista, se han recuperado fuentes de información que han aportado datos relevantes aunque se consideren, clásicamente, poco ortodoxas $^{1}$. Este enfoque multidisciplinario y el uso de diferentes fuentes han hecho ineludible un diálogo fluido entre las ciencias sociales y jurídicas, especialmente desde la sociología jurídica, y las humanidades.

"Hay otro mundo oculto a la conciencia de la ciencia: el mundo de las emociones, los sentimientos, los valores políticos; del inconsciente individual y colectivo; de las particularidades sociales e históricas que exploran las novelas, el teatro, la poesía, la música y el arte, en el que todos nosotros vivimos durante la mayor parte de nuestras horas de vigilia y de sueño, bajo la constante amenaza de su creciente exposición a la intrusión de la racionalidad científica. Parte del proyecto del feminismo consiste en poner de manifiesto la relación entre estos dos mundos"2.

En este artículo pretendemos visibilizar a las mujeresdel primer tercio del siglo XIX (1808-1814), a través del conocimiento feminista, planteado tres grandes bloques de conocimientos:

1. El empirismo feminista: mayoritariamente, las mujeres han aportado sus conocimientos a través de formatos no reglados. Unas veces porque no podían acceder a la Universidad, otras porque los varones más cercanos se apropiaron de sus producciones.

2. Los conocimientos situados: requiere explicar desde dónde se investiga, y qué cerca se está de los focos de poder o de los márgenes.

3. El escepticismo postmoderno:quizá sea el postulado más controvertido. Las características de los sujetos y del género se desdibujan. El relativismo complica la investigación en proporción a su enriquecimiento.

HARDING, Sandra, Ciencia y feminismo, Madrid, Morata, 1996, pp. 38, 137 y 208.

2 Ibídem, p. 212.

Futhark 8 (2013)

Sanchís, Las mujeres en la Guerra, 241-261

ISSN 1886-9300 


\section{II.- LA EPISTEMOLOGÍA FEMINISTA Y EL GÉNERO EN LA INVESTIGACIÓN}

Una forma de recuperar las aportaciones realizadas por las mujeres es efectuar investigaciones empleando otros paradigmas. Las epistemologías feministas, con el uso de nuevas metodologías, nos dejarán ver lo que la educación y las llamadas ciencias duras (tan neutras y objetivas) han mantenido en la sombra. Desvelar las contribuciones de las mujeres durante el periodo que abarca desde 1808 a 1814 , es lo que proponemos en esta investigación. Hermenéutica aplicada a los textos, palimpsestos que no se han descodificado porque había que ponerse las lentes feministas.

Para ello es imprescindible el análisis interdisciplinario que incluye: "desde la especulación lingüística a la fenomenología y la semiótica. Esta mutación ha hecho que cambiemos de posición frente a los textos culturales. [...] una variedad de marcos interpretativos que incluye orientaciones tan divergentes como la dialógica de M. Bajtín, la deconstrucción, la hermenéutica, las tradiciones formalistas y semióticas, el neofroidismo, los estudios del discurso del poder y sobre el cuerpo (M. Foucault, sobre todo), la deconstrucción de Jacques Derrida y las sugerencias interpretativas de Paul de Man y los estudios culturales - han servido para interrogar y valorar las perspectivas tradicionales y reformular la tarea crítica e interpretativa. Dentro de estos corpus divergentes y desiguales, las teorías feministas han ayudado decididamente a desmitificar y desenmascarar los usos ideológicos de los análisis tradicionales. Hoy debe quedar claro que ningún texto analítico puede permitirse ignorar las contribuciones fundamentales de los análisis feministas en este cambio epistémico, y en la crisis de la crítica"3.

Las mujeres, dependiendo del momento socio-económico en que nos encontremos tendrán asignados unos roles. Esta distribución pasará desapercibida hasta que no la traslademos al plano de la consciencia. $Y$ en eso tiene mucho que aportar el revisionismo investigador desde las diversas disciplinas. En la España de principios del XIX, la mujer, singular reduccionista, en tiempo de paz nominal solo podía ser el "ángel del hogar". Una vez declarada la Guerra de la Independencia, el panorama cambia sustancialmente. Partimos de dos hipótesis: la primera, es que no hay un único modelo de mujer, dato que constataremos con mayor claridad en la España sumida en la guerra; la segunda hipótesis, es que la mujer pierde derechos en época de paz nominal, afirmación que pre-

DÍAZ-DIOCARETZ, Myriam; ZAVALA, Iris M. (coord.), Breve historia feminista de la literatura española (en lengua castellana). I. Teoría feminista: discursos y diferencia, Barcelona, Antrhropos, 1993, p. 29. 
tendemos verificar por lo acontecido en el periodo constituyente y por los derechos que no les fueron reconocidos en la Constitución de 1812.

Coincidimos con Virginia Woolf cuando afirma que "el ángel de la casa" es la imagen arquetípica más dañina que sobre las mujeres han construido los varones, porque "era intensamente encantadora. Carecía totalmente de egoísmo. Destacaba en las difíciles artes de la vida familiar. Se sacrificaba a diario" 4 . De hecho, ella nos cuenta que mató al "ángel del hogar" porque si no lo hubiera hecho, él la hubiera matado a ella: "hubiera arrancado el corazón de mis escritos" 5 . Esa imagen, podemos afirmar que ha desbancando, incluso, a la de madre-virgen, cuya carga ideológica, desde los inicios del cristianismo, ha venido asentándose en sociedad y construyendo, en el imaginario colectivo del patriarcado, una mujer ideal que frustra constantemente a las mujeres reales al no poder alcanzarla. Así pues, el modelo de mujer, único, queda representado por la mujer-ángel durante el siglo XIX desbanca a la mujervirgen de los siglos anteriores; se cambia la mujer-ideal del Medievo por la mujer-criada de la Revolución industrial.

La cultura Occidental ha estructurado a los seres humanos, a la cultura y al derecho, a partir de categorías binarias, tan simples y oponibles como ineficaces. Tras una apariencia de objetividad y simetría, se esconde una clasificación inexacta, encubridora de unas relaciones asimétricas e invisiblizadoras, donde en cada par uno es el dominante y otro el dominado: varón/hembra (sic); español/indiano (sic); blanco/negro; nacional/extranjero; o rico/pobre. Otras clasificaciones, en la época que nos ocupa, no llegaron siquiera a formularse debido a que eran consideradas delito, pecado, o ambas cosas: heterosexual/homosexual o creyente/ateo. Empleamos el masculino porque es el género que se encargaba de nombrar a la humanidad. Ser mujer, lesbiana, y atea, no se concebía, recordemos que la mujer era virgen o ángel de la casa; a lo sumo podía ser mujer carnal y una perdida, pero ahí acababa el abanico binario, el resto de posibilidades, pues, eran inimaginables. Se puede observar que en cada uno de los pares propuestos, el primero es percibido como el superior, mientras que el segundo es el subordinado, el insignificante, preterición necesaria para reforzar la posición del dominante. Ambos, dominante y dominado, educados para verse en el lugar asignado y percibirse así, aceptan tales categorías sin cuestionarlas y acaban por creer que es lo natural. Se puede comprobar con facilidad que el binarismo favorece siempre a los varones en detrimento de las mujeres, convirtiéndose en la base del patriarcado; el varón es el arquetipo del ser humano.

4 WOOLF, Virginia, "Profesiones para la mujer", en SERVÉN DíEZ, Carmen (ed.) et alii, La mujer en los textos literarios, Madrid, Akal, 2007, p. 140.

5 Ibíd., p. 141. 
En el ámbito jurídico hay tres momentos claves en cuanto a consecución de derechos por parte de las mujeres: 1789, Declaración de los Derechos del Hombre y del Ciudadano; 1948, Declaración Universal de los Derechos Humanos; y 1993 Declaración de Viena, donde se explica que los derechos humanos también son derechos de las mujeres. En los tres casos, podríamos traer a colación a tres mujeres: Olympe de Gouges que en 1791 publicó la "Declaración de los Derechos de la Mujer y de la Ciudadana", obra que le costó la vida; Eleanor Roosevelt ${ }^{6}$, que junto a Hansa Metha propusieron que la Declaración Universal se denominara de los Derechos Humanos, términos más incluyentes que el de "hombres"; Radhika Coomaraswamy, abogada de Sri Lanka que fue nombrada relatora especial para la violencia contra la mujer durante la Conferencia de Viena, su labor fue investigar las violaciones de derechos humanos de las mujeres. Así pues, podemos decir que los derechos de las mujeres tienen su propia genealogía, aunque en los centros universitarios, habitualmente, solo se enseñe la de los "hombres", entiéndase, en este caso, como masculino universal.

Tras lo expuesto, ¿cómo pueden seguir llamándose las ciencias epistemológicas tradicionales ciencias neutras, si han sido capaces de dejarse fuera de sus estudios al $50 \%$ de la población mundial?, ¿cuántas otras cosas se les habrá pasado por alto en nombre de una pretendida objetividad?, ¿qué fuerza moral tienen para criticar las epistemologías feministas? Si la neutralidad ha dejado fuera a las mujeres, a toda aquella población que se aparta del patrón configurado por el varón blanco, heterosexual, creyente y burgués, consideramos que ha llegado el momento, como indican desde hace más de 20 años los estudios teóricos feministas, de aplicar otras epistemologías más incluyentes, subjetivas y mestizas que desvelen, con toda la riqueza posible, la realidad de cada momento histórico.

"Las mujeres feministas han luchado democráticamente. Violentadas ellas mismas o sensibles a la opresión de todas, no han desarrollado filosofías vengativas ni golpistas, no han imaginado mundos al revés de dominio femenino, ni sistemas de alternancia en el poder; tampoco han desplegado ideologías sexistas de tipo revanchista"7.

6 SANCHIS VIDAL, Amelia, "Eleanor Roosevelt", en AAVV, 1325 mujeres tejiendo la paz, Madrid, Icaria, 2009, pp. 218-222.

7 LAGARDE, Marcela, Identidad de género y derechos humanos la construcción de las humanas, p. 29,

http://www.upnfm.edu.hn/bibliod/images/stories/Eventos/derechos $\% 20$ humanos $\%$ 20actualizado/derechos $\% 20$ humanos $\% 20$ y $\% 20$ generos $\% 20123 /$ hambre $\% 20$ y $\% 20$ pobreza $\% 20$ dos $\% 20$ flagelos $\% 20$ que $\% 20$ continuan $\% 20 \sin \% 20$ resolverse.pdf [mayo de 2012]. 


\section{III.- LA GUERRA DE LA INDEPENDENCIA, LA CONSTITUCIÓN DE 1812 Y LAS MUJERES}

De esta manera, proponemos hacer más visibles a las mujeres y a las aportaciones que realizaron desde los diferentes lugares que ocuparon en el periodo propuesto: Guerra de la Independencia y Cortes de Cádiz. Dicho acervo, intrahistoria que podría aportar más información sobre la humanidad que las descripciones belicistas, ha quedado oculto a pesar de contener el día a día de la mayoría de los años objeto de este trabajo. La invisibilización de las mujeres, mantenida porque los análisis realizados desde modelos epistémicos feministas aún son una minoría, solo se rompe tímidamente a través del género como elemento metodológico.

Estaban al margen de la historia oficial, pero no de la responsabilidad social. Único reducto que les dejaron gestionar. Claro ejemplo fue la moda. Las mujeres de uno y otro bando, afrancesadas y fernandinas, demostraron con sus atuendos de qué lado estaban. Las primeras, afrancesadas, vestían con telas más nobles; el estilo era imperio, neoclásico, vestidos camiseros, de corte bajo el pecho y vaporosos. Su mujer señera sería Paulina Bonaparte, también llamada, de sobrenombre, la "Venus Imperial". Las segundas, fernandinas, vestían más modestamente. Eran las majas, con su corpiño, redecilla en la cabeza y falda de vuelo con mandil. Después, por cuestión también económica, tuvieron un vestido nacional, que se componía de una basquiña (falda negra) y la mantilla (blanca o negra) con la que se iba a los toros. Fue Francisco de Goya quien se encargo de popularizar esta estética tan peculiar.

Sin duda, el alzamiento del pueblo español contra los franceses fue uno de los hechos más destacados de nuestra historia contemporánea. "La guerra de Independencia, aparte de contribuir de modo considerable a la derrota napoleónica, fue valorada en toda Europa como un ejemplo excepcional [...] El modelo español sería el eje director de la 'insurrección de los pueblos' en 1813"8. En la España de principios del XIX, la mujer, solo podía ser el "ángel del hogar", pero los sucesos de 1808 hacen necesaria la participación de todos en la lucha contra el nuevo enemigo político, que lo es ahora no ya de una monarquía o una dinastía concreta sino de toda una nación. En efecto, con el inicio de la Guerra de la Independencia, donde en un contexto en el que la política lo impregna todo, los maniqueos contenidos dirigidos a las damas cambian, pues ellas forman parte de esa nueva situación en la que literatura

8 COMELLAS, José Luís, Historia de España Contemporánea, Madrid, Rialp, 2002, p. 53. 
y política se dan la mano ${ }^{9}$. A partir de estos momentos no hay un único modelo de mujer, dato que constataremos con mayor claridad en la España sumida en la guerra. Ese fue el caso de Agustina de Aragón, Agustina Raimunda María Saragossa Domenech, "La artillera", la heroína por excelencia. Sin embargo, a pesar de sus actos heroicos, no obtuvo derechos para el colectivo femenino. De otro lado, encontramos a mujeres anónimas que empiezan a dejar de serlo gracias a los estudios de género que se están realizando desde hace algunos años. Tal es el caso de María Bellido ${ }^{10}$, la aguadora de la Batalla de Bailén; o María García, "La tinajera" de Ronda ${ }^{11}$. El poeta Juan Nicasio Gallego, diputado constituyente, dijo refiriéndose a estas mujeres: "Eran muy hombres aquellas mujeres". Y efectivamente, plasmó en una frase la esencia de un imaginario social que aún pervive con pocas modificaciones sustanciales; el ideal de ser humano es el de un varón, blanco, heterosexual y católico. Era difícil imaginar otros arquetipos diferentes.

Para algunas historiadoras las mujeres supieron aprovechar el resquicio abierto por la coyuntura bélica, tanto para excitar el patriotismo y ensalzar las victorias de los soldados como para expresar su propia opción política, al tiempo que con mayor o menor timidez reivindicaban su derecho a pronunciarse en este terreno ${ }^{12}$. Era en la práctica la única

9 Como nos pone de relieve Marieta Cantos, entre 1808 y 1814 se publicó mucho en España. "Por lo general, textos informativos, publicitario de la actividad organizada de mujeres y, en alguno ocasión de colaboraciones de mujeres como María Manuela de Ulloa que es la escritora que con mayor asiduidad escribe en la prensa, para intervenir en el debate público". CANTOS, Marieta, "La literatura femenina en la Guerra de la Independencia: A la ciudadanía por el patriotismo", Revista HMiC, núm. VIII, 2010, p. 35. Sobre el papel de la mujer en la guerra léanse las páginas del artículo de Gloria Espigado titulado "Mujeres y ciudadanía. Del antiguo régimen a la revolución liberal", publicado en Debats-2003. ESPIGADO TOCINO, Gloria, "Las mujeres y la política durante la guerra de la Independencia", Ayer, 86/2012.

10 LÓPEZ PÉREZ, M., "María Bellido: una mujer para una batalla. Mito y verdad en la heroína de Bailén", en Conflicto y sociedad civil: la mujer y la guerra, Actas de las IV Jornadas sobre la Batalla de Bailén y la España Contemporánea, Jaén, Servicio de Publicaciones de la Universidad de Jaén, 2003, pp. 21-84.

11 CASTELLS, Irene; ESPIGADO, Gloria; ROMERO, M ${ }^{a}$ Cruz (eds.), Heroínas y patriotas. Mujeres de 1808, Madrid, Cátedra, 2009.

12 En los últimos años se ha publicado algunos trabajos sobre la mujer en la Guerra de la Independencia, tanto en el plano histórico como en el literario. Este último es el aspecto abordado en el artículo de $\mathrm{M}^{\mathrm{a}}$ del Carmen Simón Palmer, "De heroínas a traidoras", en CUENCA TORIBIO, José Manuel (ed.); RAMOS ROVI, Ma José; VENTURA ROJAS, José Manuel (coord.), Andalucía en la Guerra de la independencia (1808-1814), Córdoba, Servicio de Publicaciones, 2009, pp.415-425. CANTOS CASENAVE, Marieta, "Las mujeres en la prensa entre la llustración y el Romanticismo", en CANTOS CASENAVE, M.; DURÁN LÓPEZ, F.; ROMERO FERRER, A. (eds.) La guerra de pluma. Estudios sobre la prensa de Cádiz en el tiempo de las Cortes (1810-1814). Tomo III. Parte quinta: Sociedad y consumo: 
opción que les quedaba, ya que como veremos a continuación, pronto se les prohibió el acceso a las sesiones parlamentarias y, con ello, a la política $^{13}$.

A finales de 1808 Sevilla acogió a la Junta Central, lo que acabó en una reunión de las Cortes en Cádiz en septiembre de 1810. No parece pertinente en estas líneas detallar los acontecimientos que tendrían lugar en los meses siguientes; sí cabe señalar los principales hitos: la proclamación de la soberanía nacional -24 de septiembre-, el nombramiento de la comisión encargada de preparar el proyecto de Constitución -23 de diciembre de 1810-, el traslado de las Cortes de la Isla de León a Cádiz-24 de febrero de 1811-, o la publicación de la Constitución -19 marzo $1812^{14}$.

La extensa Carta Magna promulgada el 19 de marzo de 1812 (razón por la que fue castizamente llamada "La Pepa") consta de diez títulos y 384 artículos. En este texto se habla de España (definida según el artículo $1^{\circ}$ como "la reunión de todos los españoles de ambos hemisferios"), de los españoles (en el artículo $3^{\circ}$ se dice que "la soberanía reside esencialmente en la Nación"), los tres poderes (en sus arts. 15 al 17, legislativo, ejecutivo y judicial), las distintas funciones ministeriales $y$, finalmente, la Constitución se contempla y regula a sí misma ${ }^{15}$. Asimismo, España se declara una monarquía moderada hereditaria (art. 14) y confesional católica (art. 12).

Estas Cortes reunidas en Cádiz, aisladas del resto del país, estaban realizando en España el tránsito del Antiguo al Nuevo Régimen. Pero desde el principio, las mujeres estuvieron excluidas de la esfera pública.

estructuras de la opinión pública, Cádiz, Servicio de Publicaciones de la Universidad de Cádiz, 2008, pp. 157-334. De la misma autora véase: "Lectura femenina de la prensa política de las Cortes de Cádiz", en GARCÍA TEJERA, C.; MORALES SÁNCHEZ, I.; HERNÁNDEZ, J. A. (eds.), Lecturas del Pensamiento filosófico, político y estético. Actas del XIII Encuentro de la llustración al Romanticismo, Cádiz, Universidad de Cádiz, 2007, pp. 199-210.

13 RAMOS ROVI, Ma José; SANCHIS VIDAL, Amelia, "Las mujeres en el Cádiz de las Cortes", AH. Andalucía en la Historia, núm. 37 (julio 2012).

14 ARTOla GALlego, Miguel (ed.), Las Cortes de Cádiz, Madrid, Marcial Pons, 1991. CABALLERO MESA, F., La política andaluza en las Cortes de Cádiz, Málaga,Librería Ágora, D.L., 1991. SOLIS, Ramón, El Cádiz de las Cortes. La vida en la ciudad en los años de 1810 a 1813, Madrid, 2000. Con motivo del bicentenario de las Cortes de Cádiz han visto la luz muchos monográficos, pero resulta de especial interés el estudio bibliográfico de unos de los últimos números de la revista Ayer. CANTOS CASENAVE, Marieta; RAMOS SANTANA, Alberto, "Las Cortes de Cádiz y el primer liberalismo. Elites políticas, ideologías y literatura. Aportaciones y nuevos retos", Ayer 85/2012, pp. 23-47.

15 Sobre el entramado de la redacción de la Constitución de 1812 véase la introducción realizada por Luis Sánchez Agesta al libro de ARGÜELLES, Agustín, Discurso preliminar a la Constitución de 1812, Madrid, Centro de Estudios Constitucionales, 1989. 
Esa exclusión puede verse en los Diarios de Sesiones de las Cortes donde se relata en la sesión parlamentaria secreta del 26 de septiembre de 1810 que,

"[...] convendría disponer que las mujeres no tuviesen entrada en las galerías de la sala, y sí solo los hombres sin distinción [...] Las Cortes lo estimaron así, a favor del mejor orden, y se extendieron las siguientes proposiciones: que se niegue la entrada a las mujeres, que no se admita público sino en las galerías y que en las galerías se admitan los hombres sin distinción alguna"16.

Con esta acta comenzaba a escribirse el libro de las "innombrables", porque ya se sabe que lo que no se nombra no existe, y aquellas mujeres comenzaban a tener menos derechos que los esclavos -los hombres accedían sin distinción alguna-. En todo ello adivinamos un pacto masculino de silencio y comodidad. El siguiente capítulo, de este hipotético libro, lo encontraremos en el Reglamento para el gobierno interior de las Cortes, aprobado el 24 de noviembre de 1810, donde se prohibía el acceso de las mujeres a los espacios públicos.

"No se permitirá á las mugeres la entrada en ninguna de las galerías de la sala de sesiones. Los hombres de todas clases podrán indistintamente asistir á ellas, quedando libre, y á disposición del cuerpo diplomático extrangero, y de los Generales en gefe de Iso exércitos de las naciones aliadas y los de España, la primera division de la galería baxa á la derecha del dosel" (Grafía original de la época y subrayado nuestro) ${ }^{17}$.

A lo largo del texto de la Constitución de 1812 encontramos el retrato de unas féminas incapaces, tanto que se las denomina hembras en muchas ocasiones; lo que no ocurrirá con los varones, que en ningún momento se les llama machos. Los padres constituyentes, consecuentes con esa denominación, dejan a las mujeres capiti disminuidas para ejercer sus derechos como ciudadanas ${ }^{18}$. No pueden, entre otras cuestiones, votar ni ser votadas, ostentar cargos de representación o actuar en el tráfico mercantil. En otro orden, sirva como ejemplo el art. 25 del citado texto, donde se dice que, el ejercicio de los derechos de ciudadanía puede suspenderse, entre otras razones, por no saber leer y escribir. Es discriminatorio para las mujeres, desde el momento en que no tienen los mismos derechos ni las mismas facilidades de acceso a la instrucción. Otro ejemplo, lo encontramos en el art. 174 que habla de "varones y

16 Diario de Sesiones a Cortes. Actas Secretas de las Cortes, 26 de septiembre de 1810, p. 2.

17 Diario de Sesiones a Cortes. Actas Secretas de las Cortes, 24 de noviembre de 1810.

18 ESPIGADO TOCINO, Gloria, "Mujeres y ciudadanía: del Antiguo Régimen a la Revolución Liberal", DEBATS-2003. http://webs2002.uab.es/hmic/2003/ [mayo 2012]. 
hembras" para la sucesión al Trono en relación al art. 176 donde se dice "en el mismo grado y línea los varones prefieren á las hembras", encontrando las mismas referencias en el art. 180. Referirse a las mujeres como hembras, será de lo más descriptivo, pues esa es la función que les aguarda, la puramente biológica. Las actividades extradomésticas quedaran al alcance de una pocas, y siempre pagarán un alto precio en lo personal.

Comprobamos que el uso de la voz varones, construcción cultural, para designar a los hombres y el de hembras, realidad biológica, para designar a las mujeres, nos describe la consideración que tenían ambos sexos en la España del XIX. Las unas parían criaturas, y los otros ideas; no pensaron que las primeras podían hacer ambas cosas. En Cádiz, en sus Cortes, venció la Sofía de Rousseau ${ }^{19}$ y no las mujeres retratadas por Mary Wollstonecraft.

Si tenemos en cuenta que, el art. 25 de la Constitución de 1812 exigía saber leer y escribir para ejercer los derechos otorgados a la ciudadanía, encontramos una fuerte conexión entre la educación y los derechos políticos. La primera enseñanza era considerada indispensable a tenor de lo exigido en el art. 25.6 y 366 de la Constitución, para que en el año 1830 pudieran ejercer los derechos de ciudadanía ${ }^{20}$. El programa mínimo, recogido en el art. 10 del Proyecto de 1814, repetía lo citado en la Constitución: lectura, escritura, cálculo y catecismo religioso, y formación cívico-política, contemplando la posibilidad de incluir otros conocimientos. Sin embargo, el desarrollo legal posterior que hemos analizado constata que las mujeres quedan en bloque condenadas a ser ciudadanas de segunda clase. A pesar de que años antes, Inés Joyes y Blake en su "Apología de las mujeres" publicada en la introducción de la novela inglesa Rasselas, prince of Abissinia (1798) hiciera una de las críticas más incisivas sobre la desigualdad de los sexos en materia de educación. Critica la formación de las mujeres basada, mayoritariamente, en cultivar la apariciencia y las artes de agradar ${ }^{21}$. Esta mujer pertenecía a

19 Para el filósofo, las mujeres y los hombres son esencialmente diferentes: "Consultad el gusto de las mujeres en las cosas físicas y que dependen del juicio de los sentidos; el de los hombres en las cosas morales y que dependen del entendimiento". ROUSSEAU, J. J., Emilio o de la Educación, Madrid, EDAF, 1977, p. 382.

20 Art. 25.6 de la Constitución de 1812: "Desde el año de mil ochocientos treinta deberán saber leer y escribir los que de nuevo entren en el exercicio de los derechos de Ciudadano". Constitución Política de la Monarquía Española de 19 de marzo de 1812 (grafía original de la época), http://constitución.rediris.es/principal/ [mayo de 2012].

21 Sobre la biografía de esta y otras ilustradas puede verse el excelente trabajo de BOLUFER PERUGA, Mónica, Mujeres e ilustración. La construcción de la feminidad en la llustración española, Valencia, Diputació de Valéncia, 1998. BOLUFER PERUGA, Mónica, "Inés Joyes, autora de la 'Apología de las mujeres'. En defensa de las mujeres en la Andalucía de la llustración", Andalucía en la Historia. Ah, abril 
una familia de comerciantes irlandeses. Esto motivó que estuviese alejada de los ambientes cortesanos en los que desenvolvían las grandes ilustradas españolas, como la condesa de Montijo o las duquesas de Alba y Osuna. Sin embargo, no le impidió leer los trabajos de Josefa Amar, Discurso sobre el talento de las mujeres (1786), Discurso sobre la educación física y moral de las mujeres (1790) y conocer el estudio de Mary Wollstonecraft, Vindication of the Rights of Woman (1792).

Hubo también hombres que reivindicaron la educación para las mujeres. Por su parte Nicolás Condorcet recomendará que la instrucción debería ser la misma para mujeres que para hombres; basó su afirmación en cuatro puntos clave: 1.- Para que puedan vigilar la educación de sus descendientes; 2 .- Porque si no se instruyeran introducirían la desigualdad y la infelicidad en la familia; 3.- Porque los hombres conservarían lo aprendido si lo pudieran compartir con su mujer; 4.- Porque la mujer tiene el mismo derecho a la instrucción pública que el hombre ${ }^{22}$. Con la reforma para la enseñanza elaborada por Jovellanos y la promulgación de la Constitución, los diputados mostraron una urgente preocupación por una ley general de instrucción pública. A tal efecto, Manuel José Quintana redactó en 1813 un informe de gran trascendencia para el futuro de la educación: Informe para proponer los medios de proceder al arreglo de los diversos ramos de instrucción pública, convertido en norma en 1821 con algunas modificaciones. Es una exposición de principios básicos en la que se defiende que la instrucción debe ser igual, universal, uniforme, pública y libre. Debemos aclarar que por universal se entendía la educación para varones que, además, tuvieran unas determinadas condiciones económicas y sociales. Las mujeres no entraban en pie de igualdad en ese concepto de "universalidad".Según el Dictamen de Quintana, la instrucción de las mujeres convenía -no especifica a quién- que fuera privada o doméstica, al contrario que la de los hombres, que debería ser pública. En ambos casos, mujeres y varones deberían tener una formación religiosa ${ }^{23}$.

Como hemos visto, la Constitución de 1812 fue el primer texto fundamental de la nación en el que se declaran y regulan los derechos de los españoles. Ciertamente que se tratan de derechos muy limitados, pero el mérito de la Constitución estribó en declararlos por vez primera,

2011, pp. 80-83. De la misma autora véase "Inés Joyes y Blake: una ilustrada, entre privado y público", en CAPEL MARTíNEZ, Rosa Ma (coord.), Mujeres para la historia, Madrid, Abada Editores, S.L., 2004, pp. 27-56.

22 CONDORCET, Nicolás, Cinco memorias sobre la instrucción pública y otros escritos, Madrid, Ediciones Morata, 2001, pp. 110 y ss.

23 SANCHIS VIDAL, Amelia, "La educación pública y católica: del afrancesamiento a Cádiz", en CUENCA TORIBIO, José Manuel (ed.); RAMOS ROVI, Ma José; VENTURA ROJAS, José Manuel (coord.), Andalucía en la Guerra de la independencia (1808-1814), Córdoba, Servicio de Publicaciones, 2009, pp. 397-414. 
no como gracia benévola y paternalmente por el rey, sino declarados imperativamente por la voluntad de la nación. Si analizamos los artículos de nuestra primera carta magna vemos que, el masculino empleado en aquella época era exclusivo y excluyente; incluso las mujeres, para referirse a ellas mismas hablaban en masculino -en este caso universal e incluyente-. Qué buen aliado es el lenguaje para quienes ejercen el poder, siempre va en contra de quienes aspira a disfrutar del mismo.

\section{IV.- RESCATANDO LAS ACTIVIDADES DE ALGUNAS MUJERES.}

A pesar de la prohibición de que las mujeres participaran en la esfera pública hay referencias en la literatura de su presencia en el Parlamento. Por ejemplo, Alcalá Galiano en sus memorias menciona la presencia clandestina de algunas mujeres vistiendo ropa de hombre en las Cortes de Cádiz. Por su parte, Benito Pérez Galdós en su recreación literaria del Episodio Nacional Cádiz, introduce a la mujer en la vorágine dialéctica de los debates parlamentarios presenciados desde la galería de San Felipe Neri ${ }^{24}$.

Años antes, en 1787 la Sociedad Económica Matritense creó en su seno una Junta de Damas de Honor y Mérito. Sin embargo, coincidimos con Mónica Bolufer, no consideramos esto como un avance para las mujeres. Más bien cabe considerarlo como una negociación dentro de los límites de lo socialmente tolerado. "Si se permitía y aún celebraba la presencia de las mujeres en estos ámbitos era a condición de definir fronteras, de señalar cómo debían actuar la perfecta lectora y la escritora modélica [...], así como cuáles eran los terrenos en los que debían moverse la dama reformista y caritativa"25. Nos han llegado referencias de que, algunas mujeres tuvieron la posibilidad de acceder al espacio público y participar en los debates o en la vida social, pero su singularidad las apartó del colectivo femenino al que pertenecían. Fueron criticadas, pues, por varones y mujeres, y la realidad limitó su marco de actuación. Así, encontramos mujeres-arquetipo que vivieron un "femenino singular" en soledad, aisladas de otras mujeres cuyo rol era el de la maternidad con sus tareas reproductivas. Era como si al pisar el ámbito público, la mujer quedara contaminada a la vez que "elegida para la gloria". Si los varones las convertían en mujeres excepcionales, no haría falta reconocer la valía del colectivo al que pertenecían. Así se evitaba

24 PÉREZ GALDÓS, Benito, Cádiz, Madrid, ed. Cátedra, 2003, capítulos VIII y IX pp. 182-198.

25 BOLUFER PERUGA, Mónica, Mujeres e ilustración..., p. 299. 
que el resto de mujeres también tuviera derecho a tener derechos. Decirle a una mujer que era única fue un elogio envenenado.

De otro lado, encontramos mujeres formadas que desde las tertulias, proclamas y diversos actos, fueron inscribiendo su presencia y su voz en los bordes de una cultura política que las marginaba. Durante estos años se dieron cita, sobre todo en Cádiz, las tertulias de dos mujeres muy influyentes: las protagonizadas por Margarita de Morla, de tendencia liberal y educada en Inglaterra y la de Frasquita Larrea y Aherán, conservadora. Margarita formuló teorías de reforma social de corte utópico que se reflejaban en sus discursos. En cuanto a Frasquita Larrea, más conocida por ser esposa del literato alemán Böhl de Faber, se subraya su catolicismo exacerbado y su hostilidad frontal al liberalismo ${ }^{26}$. Sin duda, Frasquita Larrea, fue una mujer poco convencional que, se inserta en los círculos culturales de su época, llegando a decir de ella que tenía un "tradicionalismo sospechosamente antiliberal"27. Sin embargo, ese conservadurismo no le impidió reivindicar derechos para las mujeres. Frasquita poseía una vasta cultura que le permitió leer a Lord Byron, analizar las obras de Mary Wollstonecraft, e incluso traducir Vindicación de los derechos de la mujer que adoptó como lectura de cabecera al reconocerse a sí misma como un ser mutilado, cercenado en todas sus posibilidades de desarrollo personal. Su reivindicación propia es la misma que expresan otras mujeres de su época en otros lugares; por tanto, es considerada como la precursora del feminismo en España. A una reivindicación personal se une una conciencia colectiva, donde se busca más allá del propio interés, para alcanzar los intereses y los derechos de las mujeres. No obstante, esta escritora, a veces, es mencionada como la madre de la novelista "Fernán Caballero", seudónimo de Cecilia Böhl de Faber, y pocas veces recordada como lo que fue: una de las primeras románticas europeas y una feminista avant la lettre.

Frasquita Larrea, desde 1808 había hecho uso de esa libertad de facto para escribir, pero andando el tiempo se mantendría más reticente, sobre todo si, como sostenía también María Manuela López de Ulloa, se utilizaban los papeles públicos para censurar al rey o a las autoridades religiosas. Desde luego no sentía el mismo recelo si de lo que se trataba era de poner en tela de juicio la actuación de las mismas Cortes y por eso su folleto Fernando en Zaragoza (1814) fue denunciado a la censu-

26 PASCUA SÁNCHEZ, Ma José ; ESPIGADO TOCINO, Gloria (eds.), Frasquita Larrea y Aherán. Europeas y españolas entre la llustración y el Romanticismo (1750-1850), Cádiz, Universidad de Cádiz y Ayuntamiento de El Puerto de Santa María, 2003.

27 CANTOS, Marieta, "El patriotismo anticonstitucional de una mujer gaditana: Frasquita Larrea (1775-1838), en La llusión constitucional. Pueblo, Patria y Nación. Actas del XI Congreso de llustración y Romanticismo, Cádiz, Servicio de Publicaciones de la Universidad de Cádiz, 2004, pp. 129-142. 
ra. Ante la denuncia, Frasquita manifestó que ella tenía "entendido que el artículo 371 de la Constitución permitía la publicación ilimitada de ideas políticas" y que lo que había escrito lo había hecho inspirada en las encontradas opiniones que mantenían los papeles públicos, incluidos entre estos los de Inglaterra, Francia y Alemania. Frasquita siguió escribiendo no publicó nada más y en los últimos años se centró en lanzar la carrera literaria de su hija Cecilia Böhl de Faber, conocida años después como "Fernán Caballero"28.

No debemos pasar por alto, que durante aquellos años de la contienda contra Napoleón, Frasquita puso su pluma al servicio de su idea de una España regida por un monarca absoluto, defensor de los derechos tradicionales y de la religión católica. La recompensa de tanta declaración absolutista no se hizo esperar. En el Archivo Osborne recordemos que Tomás Osborne fue su yerno- sus biógrafas han encontrado un certificado manuscrito sobre la pertenencia de Frasquita Larrea a la "Junta Patriótica de Señoras de Cádiz", firmado por Loreto Figueroa y Montalvo el 17 de octubre de 1815. En el verano de 1818 entró a formar parte de la Clase de Damas de la Sociedad Económica de Amigos del País. La gaditana dedicó parte de su tiempo a ordenar los muchos apuntes recogidos sobre las costumbres de la Baja Andalucía. Algunos de estos borradores se los mostró al historiador americano Washington Irving, cuando se hospedó en su casa del Puerto de Santa María durante el viaje realizado en 1828 por tierras andaluzas.

Estas damas no querían quedarse al margen de los acontecimientos de la época y redactaron tres folletos dirigidos al rey de Inglaterra Jorge III. En el primero, Representación de las Damas españolas a Jorge $3^{\circ 29}$, impreso en Cádiz y reimpreso en varios lugares. se expresa la duda sobre el papel del ejército inglés va a jugar en la guerra contra Napoleón con la velada sospecha de que la debilidad española sería beneficiosa para la independencia de las colonias americanas y para la posición de Inglaterra en Europa. En el segundo, Declaración de las Damas españolas, hay una cierta rectificación de lo dicho ${ }^{30}$. El tercero es enviado cuando ya ha quedado clara la posición de Jorge III, su gobierno y su participación en la guerra española:Congratulatoria que dirigen a Jorge

28 GIL NOVALES, A., "Fuentes hemerográficas para el estudio de la Guerra de la Independencia", en ACOSTA MARTÍNEZ, F. (coord.), Bailén a las puertas del Bicentenario: revisión y nuevas aportaciones, Jaén, Universidad de Jaén, 2008, pp. 316-317.

29 Representación de las Damas españolas a Jorge $3^{\circ}$, rei de Inglaterra sobre los vagos rumores acerca de la conducta del gobierno inglés y de sus exercitos en la guerra de España,Cádiz, Imprenta de Jiménez Carreño, 1811, 23 p.

30 Declaración de las Damas españolas sobre la Representación que a su nombre se ha hecho a S.M.B sobre los vagos rumores acerca de la conducta del gobierno inglés y de sus exércitos en la guerra de España, Cádiz, Imp. de Niel, 1811, 18 p. 
Tercero, Rey de Inglaterra, por los triunfos de sus exercitos y las glorias de Wellington ${ }^{31}$, firmado de nuevo por las mismas "damas españolas", y que muestra el agradecimiento al monarca.

Como vemos, las mujeres, como colectivo con conciencia de grupo, querían tener los mismos derechos que los varones, porque de los deberes siempre habían "disfrutado"32. Mujeres como la Condesa Bureta, María Consolación de Azlor y Villavicencio que era prima de Palafox, empleó su dinero en atender a la población en el asedio zaragozano y luchó contra los franceses. Otra mujer destacada fue María Tomasa de Palafox y Portocarrero, marquesa de Villafranca y duquesa de Medina Sidonia. Esta pintora era hija de la condesa de Montijo, una gran ilustrada de la época que disfrutó de una enorme actividad social inédita para las mujeres por aquellos años, dotando a su hija de una magnífica educación. En 1805, Tomasa de Palafox fue nombrada académica de la Real Academia de San Fernando y, en 1811 fundó en Cádiz, la Sociedad Patriótica de Señoras de Fernando VII33.

En estos primeros años fue muy escasa la participación femenina en la prensa andaluza. Como novedad, algunas escritoras empezaron a asumir funciones de edición y dirección de algunos de estos periódicos. Reseñar el papel desempeñado por Carmen Silva ${ }^{34}$ que sustituyó a su esposo represaliado en la dirección de El Rodespierre Español, en el Cádiz de 1812. Desde el 1 al 13 de marzo de 1813 se publicó en Cádiz un periódico con el título de El Amigo de las Damas ${ }^{35}$. Con una duración de 7 números estaba dirigido específicamente a mujeres. Con anterioridad en Cádiz se publicó La Pensadora Gaditana. Desde sus páginas se difundió la concepción doméstica de la mujer, no considerada por sí misma, sino limitando sus facultades a la imaginación y a la sensibilidad. Esta idea que se tiene en el Cádiz de la Cortes de la mujer no es del todo ajena a la concepción rousseauniana que dominaba Europa.

31 Congratulatoria que dirigen a Jorge Tercero, Rey de Inglaterra, por los triunfos de sus exercitos y las glorias de Wellington, por Las Damas Españolas, Cádiz, Imprenta de Don Manuel Ximenez Carreño, 1812, 23 p.

32 Actualmente estamos investigando cómo las mujeres juraron la Constitución gaditana de hecho aunque no de derecho.

33 ESPIGADO, Gloría, "Mujeres y ciudadanía..., p. 181.

34 Sobre la labor realizada por Carmen Silva al frente de El Robespierre Español puede consultarse el trabajo de SÁNCHEZ HITA, Beatriz, "María del Carmen Silva, la Robespierre Española: una Heroína y Periodista en la Guerra de la Independencia", en CASTELLS, I.; ESPIGADO, Gloria; ROMEO, Ma Cruz (coord.), Heroínas y Patriotas. Mujeres de 1808..., pp. 399-425.

35 SÁNCHEZ HITA, Beatriz, "Prensa para mujeres en Cádiz después de 1791: el Correo de las Damas (1804-1807) y El Amigo de las Damas (1813)", Cuadernos de Ilustración y Romanticismo, Revista del Grupo de Estudios del Siglo XVIII de la Universidad de Cádiz, núm. 11 (2003), pp. 111-147. 
Por su parte, $\mathrm{M}^{\mathrm{a}}$ Manuela López de Ulloa irrumpió en el panorama periodístico el 24 de diciembre de 1812, al insertar en el periódico reaccionario El Procurador General de la Nación y del Rey un artículo firmado por "M.L.". Al año siguiente volvería a publicar en el mes de febrero pero ya en la etapa madrileña de este periódico y con el seudónimo de La española en la Corte C. $^{36}$.

A comienzos del siglo XIX, no sin sortear serias restricciones impuestas por la monarquía de Carlos IV, el barón de Bruère edita en Cádiz (1804-7), El Correo de las Damas dejando muy claro el objetivo didáctico de la empresa encaminada a aportar "ideas y ejemplos útiles" a las lectoras "para hacerlas buenas ciudadanas, fieles esposas y tiernas madres de familia", en una clara expresión de que el valor cívico de las mujeres se forjaría a partir del comportamiento observado en el entorno doméstico. Poco después, ve la luz El Amigo de las Damas que, con El Tío Tremenda promueven la educación de la mujer en atención al papel que juega en la sociedad, su concepción es bien distinta, pues la primera publicación destaca la importancia de que las damas conozcan el nuevo código y lo difundan a los futuros ciudadanos, mientras que la segunda destaca la importancia de la Religión y la virtud como conceptos claves, rechazando al mismo tiempo un rol concreto en la sociedad, ya que al fin y al cabo su formación se convierte en un instrumento de felicidad individual ${ }^{37}$.

Concluimos exponiendo que la mayoría de las veces, esas vindicaciones, a través de tertulias, proclamas y otros actos veladamente reivindicativos, no pasaron de la esfera doméstica, y rara vez alcanzaron la prensa o la relevancia pública que merecían. Desde distintos puntos de la geografía española, las mujeres intentaron hacer oír su voz con fórmulas no exentas de ingenio; unas veces presentándose al público revestidas de la sagrada misión de madres y esposas, y otras disfrazadas de varones. En Cádiz, en sus Cortes, venció la Sofía de Rousseau y no las mujeres retratadas por Mary Wollstonecraft. Venció la mujer en la casa y "con la pata quebrada", no las ciudadanas que disfrutan de los mismos derechos que los varones. Venció la hembra-objeto que pare, ora y trabaja, mientras que el varón-sujeto solo tuvo que nacer para obtener sus derechos. Tener riquezas, en ambos casos, siempre ayudaba.

36 CANTOS, Marieta; SÁNCHEZ HITA, Beatriz, "Escritoras y periodistas ante la Constitución de 1812 (1808-1823)", Historia Constitucional, 10 (2009) http://www.historiaconstitucional.com [mayo 2012].

37 SÁNCHEZ HITA, Beatriz, "Prensa para mujeres en Cádiz después de 1791. El Correo de las Damas (1804-7) y El Amigo de las Damas (1813)", Cuadernos de Ilustración y Romanticismo, 11 (2003), pp. 111-147. 


\section{V.- CONCLUSIONES.}

I. Las epistemologías feministas, con metodologías de género, son más efectiva que las epistemologías clásicas para visibilizar las aportaciones de las mujeres en la historia.

II. El análisis jurídico, desde dichas epistemologías y metodologías, son más reveladoras para obtener un diagnóstico de la evolución en la consecución de los derechos de las mujeres.

III.La mujer está discriminada con respecto al varón doblemente. Tiene restringido el derecho a la educación y carece de los derechos que ofrece la ciudadanía. Además de las sexuales, hubo otras discriminaciones en el texto constitucional y en la legislación educativa que hemos analizado. Jovellanos, Quintana o Calomarde, a pesar de sus buenas intenciones y sus lecturas de Condorcet, no equipararon los derechos educativos de las mujeres al de los varones.

IV.Tras el análisis realizado con la metodología descrita, podemos concluir que:

a. Las mujeres están bien consideradas para librar batallas, pero no para obtener derechos.

b. Las mujeres están preteridas con respecto a los varones en tiempos de paz pero salen favorecidas en tipos de crisis.

c. Entraron en la Guerra de la Independencia, pero no en la Constitución de 1812.

d. Serán consideradas, por orden de mayor a menor uso, según el articulado de la Constitución de 1812: HEMBRAS, MUJERES, ESPAÑOLAS, pero... NUNCA CIUDADANAS.

\section{VI.- BIBLIOGRAFÍA EMPLEADA.}

ARGÜELLES, Agustín, Discurso preliminar a la Constitución de 1812, Madrid, Centro de Estudios Constitucionales, 1989.

ARTOlA GALLEGO, Miguel (ed.), Las Cortes de Cádiz, Madrid, Marcial Pons, 1991.

BOLUFER PERUGA, Mónica, Mujeres e ilustración. La construcción de la feminidad en la llustración española, Valencia, Diputació de Valéncia, 1998.

BOLUFER PERUGA, Mónica, "Inés Joyes y Blake: una ilustrada, entre privado y público", en CAPEL MARTÍNEZ, Rosa Mª (coord.), Mujeres para la historia, Madrid, Abada Editores, S.L., 2004.

BOLUFER PERUGA, Mónica, "Inés Joyes, autora de la 'Apoligía de las mujeres'. En defensa de las mujeres en la Andalucía de la llustración", Andalucía en la Historia. Ah, abril 2011.

CABALLERO MESA, F., La política andaluza en las Cortes de Cádiz, Málaga, Librería Ágora, D.L., 1991. 
CANTOS CASENAVE, Marieta, "Del cañón a la pluma. Una visión de las mujeres en la guerra de la Independencia", en España 1808-1814. De súbditos a ciudadanos, Ciudad Real, Sociedad Don Quijote de Conmemoraciones Culturales de Castilla-La Mancha y Sociedad Estatal de Conmemoraciones Culturales, 2008.

CANTOS CASENAVE, Marieta, "Las mujeres en la prensa entre la llustración y el Romanticismo", en CANTOS CASENAVE, M.; DURÁN LÓPEZ, F.; ROMERO FERRER, A. (eds.), La guerra de pluma. Estudios sobre la prensa de Cádiz en el tiempo de las Cortes (1810-1814). Tomo III. Parte quinta: Sociedad y consumo: estructuras de la opinión pública, Cádiz, Servicio de Publicaciones de la Universidad de Cádiz, 2008.

CANTOS CASENAVE, Marieta, "Lectura femenina de la prensa política de las Cortes de Cádiz", en GARCÍA TEJERA, C.; MORALES SÁNCHEZ, I.; HERNÁNDEZ, J. A. (eds.), Lecturas del Pensamiento filosófico, político y estético. Actas del XIII Encuentro de la llustración al Romanticismo, Cádiz, Universidad de Cádiz, 2007.

CANTOS CASENAVE, Marieta, "El patriotismo anticonstitucional de una mujer gaditana: Frasquita Larrea (1775-1838), en La Ilusión constitucional. Pueblo, Patria y Nación. Actas del XI Congreso de llustración y Romanticismo, Cádiz, Servicio de Publicaciones de la Universidad de Cádiz, 2004.

CANTOS, Marieta, "La literatura femenina en la Guerra de la Independencia: A la ciudadanía por el patriotismo", Revista HMiC, núm. VIII, 2010.

CANTOS CASENAVE, Marieta; SÁNCHEZ HITA, Beatriz, "Escritoras y periodistas ante la Constitución de 1812 (1808-1823)", Historia Constitucional, 10 (2009) http://www.historiaconstitucional.com [mayo 2012].

CANTOS CASENAVE, Marieta; RAMOS SANTANA, Alberto, "Las Cortes de Cádiz y el primer liberalismo. Elites políticas, ideologías y literatura. Aportaciones y nuevos retos", Ayer 85/2012.

CASTELLS, Irene; ESPIGADO, Gloria; ROMERO, Ma Cruz (eds.), Heroínas y patriotas. Mujeres de 1808, Madrid,Cátedra, 2009.

COMELLAS, José Luís, Historia de España Contemporánea, Madrid, Rialp, 2002.

CONDORCET, Nicolás, Cinco memorias sobre la instrucción pública y otros escritos, Madrid, Ediciones Morata, 2001.

DÍAZ-DIOCARETZ, Myriam; ZAVALA, Iris M. (coord.), Breve historia feminista de la literatura española (en lengua castellana). I. Teoría feminista: discursos y diferencia, Barcelona, Antrhropos, 1993.

ESPIGADO TOCINO, Gloria, "Mujeres y ciudadanía: del Antiguo Régimen a la Revolución Liberal", DEBATS-2003.

ESPIGADO TOCINO, Gloria, "Las mujeres y la política durante la guerra de la Independencia", Ayer, 86/2012.

ESPIGADO TOCINO, Gloria; SÁNCHEZ ÁLVAREZ, A. Ma, "Formas de sociabilidad femenina en el Cádiz de las Cortes", en ORTEGA, M.; Sánchez, C.; Valiente, C. (eds.) (1999), Género y ciudadanía revisiones desde el ámbito privado. XII Jornadas de Investigación interdisciplinaria, Instituto Universitarios de Estudios de la Mujer, Madrid, Universidad Autónoma de Madrid, 1999.

GIL NOVALES, Alberto, "Fuentes hemerográficas para el estudio de la Guerra de la Independencia", en ACOSTA MARTÍNEZ, F. (coord.), Bailén a las puertas 
del Bicentenario: revisión y nuevas aportaciones, Jaén, Universidad de Jaén, 2008.

GÓMEZ ARTECHE, José, "La mujer en la Guerra de la Independencia", Madrid, Establecimiento tipográfico Hijos de J. A. García, 1903.

HARDING, Sandra, Ciencia y feminismo, Madrid, Morata, 1996.

LAGARDE, Marcela, Identidad de género y derechos humanos la construcción de las humanas,

$$
\text { p. }
$$

29 , http://www.upnfm.edu.hn/bibliod/images/stories/Eventos/derechos\%20hu manos $\% 20$ actualizado/derechos $\% 20$ humanos $\% 20$ y 20 generos $\% 20123 /$ ha mbre\%20y\%20pobreza\%20dos\%20flagelos $\% 20$ que $\% 20$ continuan $\% 20 \mathrm{sin}$ $\% 20$ resolverse.pdf [mayo de 2012].

LÓPEZ PÉREZ, M., "María Bellido: una mujer para una batalla. Mito y verdad en la heroína de Bailén", en Conflicto y sociedad civil: la mujer y la guerra, Actas de las IV Jornadas sobre la Batalla de Bailén y la España Contemporánea, Jaén, Servicio de Publicaciones de la Universidad de Jaén, 2003.

MORANT, I. (dir.), Historia de las mujeres en España y América Latina. Tomo III: Del siglo XIX a los umbrales del XX, Madrid, Cátedra, 2006.

PASCUA SÁNCHEZ, Ma José; ESPIGADO TOCINO, Gloria (eds.), Frasquita Larrea y Aherán. Europeas y españolas entre la llustración y el Romanticismo (1750-1850), Cádiz, Universidad de Cádiz y Ayuntamiento de El Puerto de Santa María, 2003.

PÉREZ GALDÓS, Benito, Cádiz, Madrid, ed. Cátedra, 2003.

RAMOS PÉREZ, Demetrio (coord.), Historia General de España y América. Emancipación y nacionalidades americanas. T. XIII, Madrid, Rialp, 1992.

RAMOS ROVI, Ma José; SANCHIS VIDAL, Amelia, "Las mujeres en el Cádiz de las Cortes", AH. Andalucía en la Historia, núm. 37 (julio 2012).

Reglamento para el gobierno interior de las Cortes, Cádiz,Imprenta Real, 1810.

ROUSSEAU, Jean J., Emilio o de la Educación, Madrid, EDAF, 1977.

SÁNCHEZ HITA, Beatriz, "Prensa para mujeres en Cádiz después de 1791: el Correo de las Damas (1804-1807) y El Amigo de las Damas (1813)", Cuadernos de llustración y Romanticismo, Revista del Grupo de Estudios del Siglo XVIII de la Universidad de Cádiz, núm. 11 (2003).

SÁNCHEZ HITA, Beatriz, "María del Carmen Silva, la Robespierre Española: una Heroína y Periodista en la Guerra de la Independencia", en CASTELLS, Irene; ESPIGADO, Gloria; ROMERO, Ma Cruz (eds.), Heroínas y patriotas. Mujeres de 1808, Cátedra, Madrid, 2009.

SANCHIS VIDAL, Amelia, "Eleanor Roosevelt", en AAVV, 1325 mujeres tejiendo la paz, Madrid, Icaria, 2009.

SANCHIS VIDAL, Amelia, "La educación pública y católica: del afrancesamiento a Cádiz", en CUENCA TORIBIO, José Manuel (ed.); RAMOS ROVI, Ma José; VENTURA ROJAS, José Manuel (coord.), Andalucía en la Guerra de la independencia (1808-1814), Córdoba, Servicio de Publicaciones, 2009.

SIMÓN PALMER, M ${ }^{a}$ Carmen, "De heroínas a traidoras", en CUENCA TORIBIO, José Manuel (ed.); RAMOS ROVI, Ma José; VENTURA ROJAS, José Manuel (coord.), Andalucía en la Guerra de la independencia (1808-1814), Córdoba, Servicio de Publicaciones, 2009.

SOLIS, Ramón, El Cádiz de las Cortes. La vida en la ciudad en los años de 1810 a 1813, Madrid, 2000. 
WOOLF, Virginia, "Profesiones para la mujer", en SERVÉN DíEZ, Carmen (ed.) et alii, La mujer en los textos literarios, Madrid, Akal, 2007.

http://www.congreso.es/constitucion/ficheros/historicas/cons 1812.pdf [mayo de 2012]. 